\title{
Imagining the ideal dairy farm
}

\author{
Clarissa S. Cardoso, ${ }^{\star} \dagger$ Maria José Hötzel,† Daniel M. Weary, ${ }^{*}$ Jesse A. Robbins, ${ }^{*}$ \\ and Marina A. G. von Keyserlingk* \\ *Animal Welfare Program, Faculty of Land and Food Systems, The University of British Columbia, Vancouver, V6T 1Z4, Canada \\ †Laboratório de Etologia Aplicada e Bem-Estar Animal, Departamento de Zootecnia e Desenvolvimento Rural, \\ Universidade Federal de Santa Catarina, Florianópolis, 88.034-001, Brazil
}

\begin{abstract}
Practices in agriculture can have negative effects on the environment, rural communities, food safety, and animal welfare. Although disagreements are possible about specific issues and potential solutions, it is widely recognized that public input is needed in the development of socially sustainable agriculture systems. The aim of this study was to assess the views of people not affiliated with the dairy industry on what they perceived to be the ideal dairy farm and their associated reasons. Through an online survey, participants were invited to respond to the following open-ended question: "What do you consider to be an ideal dairy farm and why are these characteristics important to you?" Although participants referenced social, economic, and ecological aspects of dairy farming, animal welfare was the primary issue raised. Concern was expressed directly about the quality of life for the animals, and the indirect effect of animal welfare on milk quality. Thus participants appeared to hold an ethic for dairy farming that included concern for the animal, as well as economic, social, and environmental aspects of the dairy system.
\end{abstract}

Key words: public aspiration, cow, well-being, citizen

\section{INTRODUCTION}

The way animals are raised on farms has changed greatly over the past century, including a growth in farm size and increased technology (Fraser, 2008). Critics argue that more intensive farming practices can harm the environment, rural communities, worker safety, food quality, food safety, and animal welfare (Boogaard et al., 2010; Godfray et al., 2010; Garnett et al., 2013).

Concerns regarding dairy production include painful procedures, such as tail docking (Weary et al., 2011), and practices that are perceived to interfere with im-

Received June 8, 2015.

Accepted November 5, 2015.

${ }^{1}$ Corresponding author: nina@mail.ubc.ca portant natural behaviors, such as cow-calf separation (Ventura et al., 2013) and zero grazing (Schuppli et al., 2014). These studies provide some evidence that although different stakeholders may share similar concerns, in other instances they have opposing views. This disconnect was also observed in a recent study where farmers strongly believed that urban citizens are ignorant about agricultural practices, and thus public perceptions on agriculture should be considered irrelevant (Benard and De Cock Buning, 2013). Although there can be disagreements about the issues and potential solutions (Vanhonacker et al., 2008; Hötzel, 2014), it is widely recognized that public input is needed when developing policy on farm animal welfare standards (e.g., Groot Koerkamp and Bos, 2008; O'Connor and Bayvel, 2012).

More broadly, understanding the values of the general public may be important in the development of sustainable food animal agriculture, as the adoption of animal husbandry practices inconsistent with public expectations may undermine social sustainability (e.g., von Keyserlingk et al., 2013; von Keyserlingk and Hötzel, 2015; Weary et al., 2015). To our knowledge, few attempts have been made to solicit the views of the general public about their aspirations for specific agriculture practices (e.g., Gaymard and Bordarie, 2015). This type of research may provide valuable insights into which factors are important to the general public as well as identify potential areas of concern that, if not addressed, may hinder the sustainability of the dairy industry.

The aim of this study was to assess the views of people not affiliated with the dairy industry on what they perceived to be the ideal dairy farm and their associated reasons.

\section{MATERIALS AND METHODS}

Participants were invited to respond to a single openended question: "What do you consider to be an ideal dairy farm and why are these characteristics important to you?" They were free to express any aspects they felt were important. Data were collected via an online 
platform (Fluid Surveys, http://fluidsurveys.com/). To better characterize the participants, they were first asked several multiple-choice demographic questions before answering the study question. The survey was completely anonymous and was approved by the University of British Columbia Behavioral Research Ethics Board (H13-01466).

\section{Survey Methodology}

Participants were recruited online from the United States via Mechanical Turk (MTurk, www.mturk.com). Several studies have assessed this tool and concluded that this approach results in high-quality and reliable data (e.g., Buhrmester et al., 2011; Saunders et al., 2013; Rouse, 2015) that is more representative than many other samples (Mason and Suri, 2012; Rouse, 2015). Participants were given the following information before taking the survey: "Take a short survey asking your opinion of dairy farms. We want to know what characteristics you think make the 'ideal' dairy farm." Upon completion of the survey, participants were paid (US\$0.50). This convenience sample was intended to provide a rich and diverse set of responses achieving saturation on the topic of what characteristics make up an ideal dairy farm. These results should not be considered representative of the US population.

The survey was launched twice, 6 mo apart, once on June 10, 2014, and again January 29, 2015. The consent form for the first cohort contained the term "Animal Welfare Program" as part of the authors' affiliation, and we were concerned that this phrase may have framed some responses. Thus, for the second cohort, this phrase was not included. The MTurk platform was set to recruit 250 US respondents in each cohort (e.g., June 2014 and January 2015).

\section{Survey Analysis}

Demographic data, separated by cohort, are presented on Table 1. Open-ended responses were analyzed using the NVivo Qualitative Data Management Program (version 10, 2014; QSR International Pty Ltd., Doncaster, VIC, Australia). The analysis was based on the qualitative method described by Huberman and Miles (1994): data reduction (information is coded finding themes), data display (organization of the information allowing for conclusions to be drawn), and conclusion drawing and verification (noting of patterns and themes and using confirmatory tactics such as triangulation between 3 readers). Three trained evaluators blind to demographic information independently examined 30 randomly selected responses, breaking them down into phrases, which were then used to identify the primary themes. The 3 readers compared results and reconciled any discrepancies. The lead author then undertook the final analyses.

The thematic analyses of the responses identified 4 primary features of an ideal dairy farm, which participants justified using reasons that were coded into 2 distinct themes (Table 2). The main themes therefore arose from the responses rather than being determined a priori. Many sentences bridged more than one theme and were thus coded into multiple themes.

\section{RESULTS}

Given that we were primarily interested in the views of respondents not directly associated with dairy industry, responses from participants that identified themselves as farmers $(\mathrm{n}=7)$ were eliminated. In addition, responses that were so inarticulate that they could not be coded $(\mathrm{n}=25)$ were deleted. The remaining 468 usable responses (234 from the June 2014 cohort and 234 from the January 2015 cohort) were from 46 US states and the District of Columbia (no responses were obtained from Montana, Wyoming, Nebraska, or South Dakota).

The frequencies of themes obtained from the 2 cohorts were similar, with "cows" arising as the primary theme accompanied by the main reason "animal welfare and ethics" (Table 2). Given that the prevalence of these themes did not vary between the 2 cohorts, we concluded that including the term "Animal Welfare" in the ethics consent form for cohort 1 did not bias in these results. Therefore, data from the 2 cohorts were pooled for the qualitative analysis. Results are described according to theme, with sub-themes for the reasons. Themes are listed in order of prevalence.

\section{Features Related to the Cow}

The most commented characteristic of the ideal farm was "cow," reflecting concerns about cow treatment, specifically that the farmer or workers should treat cows well, humanely, or with kindness. For example, one respondent (Resp.) stated, "An ideal dairy farm would be one that has no mistreatment of their livestock" (Resp. C1 113).

Respondents also mentioned that cows should be allowed space to roam. This was reflected by terms such as "open space," "outside," and "on pasture where the cow could be free" ["I think a dairy farm that tries to use all natural feed and allows the cattle plenty of open space to roam and graze" (Resp. C1 13)]. Reference to pasture was cited mainly in the context of space allotments, though some respondents did not specify if they considered pasture important just to roam outside, or 
Table 1. Participant demographics of the cohorts that participated in an online survey where they were asked to respond to the question, "What do you consider to be an ideal dairy farm and why are these characteristics important to you?"

\begin{tabular}{|c|c|c|c|}
\hline Demographics & Variable & $\begin{array}{l}\text { Cohort } 1(\%) \\
\quad(\mathrm{n}=246)\end{array}$ & $\begin{array}{c}\text { Cohort } 2(\%) \\
\quad(\mathrm{n}=247)\end{array}$ \\
\hline \multirow[t]{4}{*}{ Age (yr) } & $18-24$ & 24.0 & 19.4 \\
\hline & $25-34$ & 44.7 & 50.2 \\
\hline & $35-44$ & 16.7 & 17.8 \\
\hline & $45-65$ or above & 14.6 & 12.5 \\
\hline \multirow[t]{2}{*}{ Sex } & Male & 53.3 & 58.3 \\
\hline & Female & 46.7 & 41.7 \\
\hline \multirow{7}{*}{ Level of education } & Some high school & 0.8 & 1.2 \\
\hline & High school graduate & 13.0 & 10.9 \\
\hline & Trade or vocational degree & 1.6 & 4.1 \\
\hline & Some college & 28.5 & 25.1 \\
\hline & Associate degree & 9.8 & 10.5 \\
\hline & Bachelor's degree & 38.6 & 39.3 \\
\hline & Graduate & 7.7 & 8.9 \\
\hline \multirow[t]{3}{*}{ Area of residence } & Urban & 29.7 & 21.5 \\
\hline & Rural & 19.5 & 25.9 \\
\hline & Suburban & 50.8 & 52.6 \\
\hline \multirow[t]{3}{*}{ Familiarity with dairy } & Very familiar & 10.6 & 6.1 \\
\hline & Somewhat familiar & 53.7 & 64.4 \\
\hline & Not familiar & 35.8 & 29.6 \\
\hline \multirow{4}{*}{ Involvement in dairy ${ }^{1}$} & Professional or student & 3.6 & 2.4 \\
\hline & Animal advocate & 6.1 & 4.5 \\
\hline & Not involved & 91.5 & 92.3 \\
\hline & Other & 1.6 & 2.0 \\
\hline
\end{tabular}

${ }^{1}$ Participants were allowed to self-identify in multiple roles, so the sum of percentages exceeds 100 .

to graze ["To let the cows free range on pasture" (Resp. C1 23); "The cows are all out in the pasture most of the day and then brought in to be milked and sent back to the pasture" (Resp. C2 30)]. Others were specific in their responses that cows should be fed grass: "Cows have plenty of grass to eat" (Resp. C1 20); "An ideal dairy farm would feed the cows only grass" (Resp. C1 36); "Ideally, all dairy farms should feed their cows grass" (Resp. C2 237).

Table 2. Emerging themes in response to the question, "What do you consider to be an ideal dairy farm and why are these characteristics important to you?"

\begin{tabular}{|c|c|c|c|c|c|}
\hline \multirow[b]{2}{*}{ Encoding } & \multirow[b]{2}{*}{ Main themes } & \multicolumn{2}{|c|}{ Cohort 1} & \multicolumn{2}{|c|}{ Cohort 2} \\
\hline & & $\mathrm{n}^{1}$ & $\%^{2}$ & $\mathrm{n}^{1}$ & $\%^{2}$ \\
\hline \multirow[t]{5}{*}{ Characteristics } & Cow & 208 & 62 & 211 & 57 \\
\hline & Business operation & 61 & 18 & 99 & 27 \\
\hline & Dairy products & 59 & 17 & 43 & 12 \\
\hline & Environment & 11 & 3 & 15 & 4 \\
\hline & Total $^{3}$ & 339 & 100 & 368 & 100 \\
\hline \multirow[t]{3}{*}{ Reasons } & $\begin{array}{l}\text { Animal welfare and } \\
\text { ethics }\end{array}$ & 91 & 53 & 98 & 58 \\
\hline & Milk quality & 81 & 47 & 71 & 42 \\
\hline & Total $^{3^{2}}$ & 172 & 100 & 169 & 100 \\
\hline
\end{tabular}

${ }^{1}$ Number of references codified into each theme.

${ }^{2}$ Percent relative to number of references in relation to total of sentences codified.

${ }^{3}$ Total number references codified.
Within the theme "cow," respondents also made frequent reference to desiring "naturalness" in dairy production, often referred to when speaking of space and pasture, but sometimes also referring to natural diets. For example, 2 responses were, "A farm where the animals are raised humanely, outside of cages, in a natural environment. Also a farm that doesn't mass produce unnatural animals using steroids and antibiotics" (Resp. C2 59); "One where the animals are allowed to roam freely, not confined to pens or cages, are fed an organic or natural diet" (Resp. C1 4).

Respondents did not approve of cows being injected with hormones to produce more milk, or antibiotics, unless necessary:

"They would not be fed any grain or given any drugs unless absolutely necessary. No hormones" (Resp. C1 228);

"Also, the cows wouldn't be given lots of antibiotics or other medicines to make them produce more milk" (Resp. C1 14);

"Not treated with synthetic hormones or antibiotics - unless absolutely necessary" (Resp. C2 231).

A few comments were specific to the cow-calf bond, including ["Mothers and calves should have large stalls 
with fresh bedding each day" (Resp. C1 53); "The ideal dairy farm puts the well-being of the animals above other considerations. This means, for example, not separating a new-born from the mother" (Resp. C2 54)].

Finally, participants showed concern for the health of cows, stating that cows must be healthy, without disease, and must receive veterinarian care ["Clean, free of disease and good medical care" (Resp. C2 169); "An ideal dairy farm is clean (...) and are also treated medically when they have problems" (Resp. C1 25)]. This concept was expanded by some participants to include comments on the facilities, specifying that they should be good, safe, and clean for the cows ["I think an ideal dairy farm would be a safe and clean environment for cows to live" (Resp. C1 91); "The dens or housing for the cows should be well kept and clean so the cows are healthier" (Resp. C2 190)].

\section{Reasons Related to Animal Welfare and Ethics}

Reasons presented that were ethical in nature included the quality of treatment workers or farmers should give to animals. Respondents expressed concerns that animals should be treated with "respect," "humanely," or "fairly," "kindly," "with love," and with "dignity," because it is moral or ethical.

"They [the cows] should be treated humanely because it's the right and moral thing to do" (Resp. C1 218);

"This is a humane issue and people should treat animals with respect. It is just common decency" (Resp. C2 38).

An ethical perspective was also present in the arguments that animals deserve respect. Some commented that the animals were not here only for the benefit of humans: "I do not believe that we should mistreat animals even though we are the dominant species on the planet, all life still deserves respect" (Resp. C1 13), and "The animals that provide the milk are not just a tool but living beings that give us our milk, so they deserve respect" (Resp. C2 66).

Referring to the quality of life of the animals was frequently used to justify the characteristics of the ideal farm; namely, the characteristics presented were important for participants because they were equated with a better life for the animals:

"I feel that this would allow the cows to have the best life" (Resp. C2 118);
"This is important to me both for my own health and the health and quality of life of the cows" (Resp. C1 44).

Finally, a few participants suggested that the quality of treatment given to animals at the farm could affect their consumption of dairy products, "This is important to me because I am deeply troubled and affected by cruel treatment to animals and would not want to purchase any products derived from such treatment" (Resp. C2 34), and "I don't want milk from mistreated animals" (Resp. C2 170).

\section{Features Related to the Business Operation}

The second most frequent characteristic identified by participants was associated with the business operation. This theme included characteristics about the farm as a whole, with most references indicating that the ideal farm should be profitable, productive, and efficient. Some respondents also stated that the ideal farm should be organic, small, operated by family farmers, and committed to contributing to their community (e.g., offering tours or selling their milk products locally).

"The ideal dairy farm is similar to the one local to me. It is small to medium sized and has a lot of local interest and local interaction. They mostly sell milk and cheese to local stores but sell ice cream made on site and sell it locally. (...) They also put on a lot of community events on the weekends and are always extremely busy during them. It feels like part of the community" (Resp. C1 207);

"An ideal dairy farm would be locally owned and privately managed organically. These are important characteristics that show character and inspire confidence in a business" (Resp. C1 117);

"The ideal farmer works hard to produce organic products. This is important to me because it shows that we are getting our dairy products from a reliable place" (Resp. C2 94).

Some respondents connected mistreatment of cows with the term "factory farm," and disapproved of this kind of treatment in an ideal dairy farm ["No factory farming. A more organic approach" (Resp. C1 122); "It is important to me because having seen dairy Factory Farms my heart breaks for the animals who must endure awful conditions. My hope is for the animals to be treated humanely" (Resp. C2 169)]. 
Respondents expressed some concern about the owners (farmer), stating that they should be efficient, educated, loving, and competent: "The owner cares about his animals and takes great pride in ensuring a great life for them" (Resp. C2 171). Others stated that the farmer should be honest and responsible: "Lastly, a dairy farmer has to be honest. Honesty is important with everyone, especially farmers" (Resp. C1 193). Other respondents referred to social aspects, about work conditions and involvement with the community, [e.g., "A clean safe environment for everyone involved" (Resp. C1 44); "Paying their employees a good wage also is important" (Resp. C1 151); "The staff should be friendly and machines should work nicely" (Resp. C1 244); "I think an ideal farm would be where the milking is done by machines" (Resp. C1 157); "A farm that respects the community it is in as well as the environment in the surrounding area" (Resp. C2 23)].

\section{Features Related to Dairy Products}

Respondents expressed expectations relative to the quality of milk, stating that the ideal dairy farm produces high-quality milk and other products:

"The farm would also uphold standards of health for their products" (Resp. C1 16);

"I consider a dairy farm ideal when they care about the quality of products that they sell" (Resp. C1 61).

Many respondents provided qualifiers when referring to quality, stating that this referred to the absence of antibiotics, hormones, or other chemicals in the milk, and a clean environment to produce a safe and healthy product ["They should be as natural as possible, don't use chemicals on their products" (Resp. C1 69)]. Some referred to the need to follow laws and regulations, as well as good equipment, for farms to keep the consumers safe and healthy:

"The collection of the milk must be handled with health regulations" (Resp. C2 243);

"All equipment would be clean and in perfect working order to ensure the milk doesn't get contaminated or that the equipment doesn't injure a cow" (Resp. C1 169).

\section{Reasons Related to Milk Quality}

The other main aspect that was identified by respondents involved concerns for themselves, especially their own health; simply put, they want healthy milk. Moreover, participants made explicit in their responses that they want milk and other dairy products that are high quality, clean, and safe to consume. These respondents suggested that the quality of life of a cow influences the quality of the milk she produces, which in turn influences human health:

"These [low use of antibiotics, no sacrifice of animals, good quality of products, hygienic practices and attention to detail] are important to me because it ensures that what I'm eating will be of the highest standard and acceptable in both flavour and nutritional content" (Resp. C2 73);

"I think that the better the cows are taken care of, and the healthier they are, the healthier the milk will be" (Resp. C1 96);

“...one where cows aren't given hormones because I don't like the idea of taking drugs in my food and drink" (Resp. C1 28).

Finally, several people linked the food that cows consume with milk quality, mentioning that the cow's feed should be organic, grass-based, and without hormones or antibiotics. Others associated the quality of the milk with the quality of life of the cows, and concluded that for this reason cows should be treated well: ["Grass fed cows produce, I think, better tasting products" (Resp. C1 111); "The less drugs given to them the better, so they don't pass them along to humans in their milk" (Resp. C2 222); "The cows have to be treated properly, free range not locked in pens their whole lives. Good milk comes from happy cows" (Resp. C2 3)].

\section{Features Related to the Environment}

Although only a few respondents (11 in the first cohort and 15 in the second cohort) made references that reflected concerns with environmental issues, those that did comment clearly indicated their desire that some care and responsibility about pollution and environmental effects should be part of an ideal dairy farm. Terms such as "green," "eco-friendly," and "sustainable" were used to designate the ideal dairy farm:

"A dairy farmer that gets their milk responsibly for the environment" (Resp. C2 66);

"I would say ideal would be a farm which gives back as much as it takes from the earth and strives to be a 'green' farm" (Resp. C1 52); 
"The farm is being run in an eco-friendly way"

(Resp. C1 234);

"The farm is sustainable, because it is important to respect the environment" (Resp. C2 111).

\section{Other Relevant Results}

Respondents expressed characteristics related to several aspects of a dairy farm within the same response; individual participant responses referenced on average 1.5 features. The ideal farm often included characteristics relating to the cows, milk products, environment, consumers, farmers, workers, and the community:

"Sustainable. Does not waste a lot of natural resources. Humane, not torturous for the animals. It's important for me because these things are ethical considerations for production of food" (Resp. C1 221);

"A farm that has the latest equipment and produces the best product. Where the animals are cared for and given enough room. The food fed to the animals should be high quality and not filled with chemicals or hormones" (Resp. C2 164);

"Well cared for cows, top of the line pasteurization equipment. Caring for your animals is very important, don't hurt them! Providing top quality and safe products for your consumers is also extremely important" (Resp. C2 214);

"One that produces quality milk for reasonable costs and treats animals and workers well. That is important to me because I enjoy quality milk and low prices" (Resp. C2 247);

"Fresh, green grass, happy cows, good milk. The happier the cows, the better tasting the milk, the more money can be made" (Resp. C2 225).

In a few responses, participants made reference to previous information or experiences that informed their views of the ideal dairy farm. For instance, a few individuals referred to visiting their local dairy farm. However, the majority of the comments that made reference to previous information and the resulting perception were negative. For example,

"I think the animals should be treated well. We hear too many horror stories" (Resp. C2 215);
"It is important to me to preserve animal welfare, because I think it is disturbing and horrifying how animals are treated in some dairy farms" (Resp. C1 15);

"This is important to me because I have seen first hand some dairy farms where the cows are kept in their stalls all day hooked up to the pump machines and it is pretty horrid" (Resp. C1 76).

\section{DISCUSSION}

To our knowledge, this is the first study that described characteristics of an ideal dairy farm by people not associated with the dairy industry. Participants referred to the social, economic, and ecological perspectives generally discussed in the definition of sustainability (von Keyserlingk et al., 2013). The majority of respondents $(90 \%, 419$ of total) referred to the animal in some capacity when referring to an ideal dairy farm. These concerns focused largely on animal welfare and argued that cows inherently deserve to be provided a good quality of life, and that providing a good life would have the instrumental benefit of improving milk quality for consumers.

Our research differs from previous studies in that it solicited general public views on the concept of a dairy farm rather than on specific issues such as animal welfare (e.g., Boogaard et al., 2006; Vanhonacker et al., 2008; Ellis et al., 2009; Miele et al., 2011). Instead of asking participants about experimenter-generated characteristics, we invited participants to freely express their views of an ideal farm. That animal welfare was the most cited theme, regardless of whether the term "Animal Welfare" was present on the Ethics Consent Form, indicates that the quality of treatment given to animals is a priority concern for participants. A Dutch study reported similar findings when the general public were asked their views on factors deemed most valuable to ensure the dairy farm's future, all respondents made mention of the animal (Boogaard et al., 2008).

The majority of reasons provided by participants referred to ethical arguments about the treatment of animals. In this context, respondents argued that milk production is ethically acceptable only if animals are well treated. This utilitarian view is frequently mentioned in the ethical debate about the use of animals in agriculture. Sandøe et al. (1997) stated that utilitarians believe that it is acceptable to kill animals for consumption, as long as it is predicated on the animals having a good life and that they are killed without pain. However, these authors also argue that to achieve these conditions radical changes must be implemented 
on farms to ensure that animals are being treated in this regard. Indeed, it is the moral aspect behind animal production that has emerged from interested people that has guided much of the debate about farm animal welfare (Fraser et al., 1997). We suggest that these insights provided by the respondents in this study indicate that providing assurance that animals are well cared for will improve the acceptability of dairy farming to people who are not affiliated with the dairy industry.

Respondents focused largely on 2 aspects of animal welfare (as defined by Fraser et al., 1997): first, comments linked to the concept of natural living, including that the animals be provided access to space and pasture. Participants also made reference to the animal's health, central to the concept of biological functioning. Concerns about natural living have been reported in many other studies on public perceptions about farm animal welfare (Prickett et al., 2010). Lassen et al. (2006) reported that living a natural life was an important part of animal welfare for the general public. Vanhonacker et al. (2008) reported that the general public is concerned with an animal's ability to engage in natural behaviors. Several European studies showed that citizens valued space and pasture, and outdoor grazing as important components of animal welfare (Boogaard et al., 2008; Ellis et al., 2009; Boogaard et al., 2010; Miele et al., 2011). One recent North American study reported that the general public demonstrated preference for systems that provide some pasture access to cows (Schuppli et al., 2014), a point also raised by many of the participants in our study. Dairy farms that incorporate some form of pasture (e.g., diversified or mixed systems) could contribute to sustainability of dairy industry in 2 ways: environmentally, given that they have reduced water requirements (Mekonnen and Hoekstra, 2012) compared with zero grazing or pasture-based systems; and socially, given that they resonate with public values (see also Schuppli et al., 2014). Thus, we suggest that some form of access to pasture should be part of any future discussions regarding the sustainability of the dairy industry, despite conflicting evidence from different studies on the effects of pasture access on milk production (White et al., 2002; Fontaneli et al., 2005; Chapinal et al., 2010). Interestingly, although the participants in the current study mentioned productivity and profitability as desired characteristics of the ideal farm, they did not question the potential economic implications of including other desired characteristics of what makes up an ideal dairy farm.

For $22 \%$ of respondents the most important characteristic was related to dairy products, which was sometimes related to human health. Interestingly, milk quality was associated with qualifiers such as organic, green, local, small-scale, and family-run operations. Others that referred to concerns about milk quality focused on the ideal dairy farm having cows that did not receive any hormones or unnecessary antibiotics. Desiring practices that do not rely on hormones highlights the disconnect between standard industry practices and what participants view as ideal; exogenous hormones are frequently used on many farms to address challenges associated with low fertility (Moore and Thatcher, 2006) and to increase milk production (Bauman, 1992). Given that respondents clearly rejected the use of these technologies, our results suggest that continued reliance on them may undermine the sustainability of the dairy industry (von Keyserlingk et al., 2013). Although $22 \%$ of respondents rejected the use of antibiotics and exogenous hormones as means to increase milk production, some did specifically endorse the use of antibiotics when cows were ill (by stating that cows should be treated when necessary), suggesting a desire for naturalness but not at the expense of animal welfare.

Most of our participants made reference to aspects associated specifically with dairy farming and thus were not completely naïve of farm practices. Many volunteered information referring to the use of hormones or antibiotics and the associated effects on milk quality and human health, as well as animal rearing practices such as early cow-calf separation and the environmental effect of dairy farming. Several studies have reported differences in the assessment of animal welfare between farmers and people not associated with animal production (Te Velde et al., 2002; Vanhonacker et al., 2008; Miele et al., 2011). This has prompted some to suggest the need to facilitate consensus building between stakeholders, including farmers and general public, on animal welfare issues (Poletto and Hötzel, 2012; von Keyserlingk and Hötzel, 2015).

Some respondents also referred to modernity as important for the ideal dairy system. In general, respondents desired a mix between an industrial and agrarian view of agriculture. Thompson (2012) points out the presence of 2 types of public philosophies of agriculture: the industrial philosophy that sees agriculture as a business, and just one of many sectors in the industrial economy, which should be efficient and not cause risks to third parties; and the agrarian philosophy, which is more concerned with other issues of agriculture, such as ecosystem services, good nutrition, and food security. Participants of our survey showed interest in having access to high-quality food, which they equated with a more natural production system [e.g., with no (or limited) antibiotics and cows grazing], which was also linked, often simultaneously, with the animal's quality of life, and with human health. However, many participants were clear that this does not mean that they 
expect that farmers should produce in the same way as when the production was less technological and less profitable. As Boogaard et al. (2010) concluded, the general public wants it all: they prefer naturalness and tradition, but also value modernity in dairy production.

A variety of reasons may explain why animal welfare concerns were emphasized in the comments in this survey. First, it seems reasonable that after 6 decades of public debate and the presence of organized animal protection groups (reviewed by von Keyserlingk and Hötzel, 2015), society may have internalized animal welfare as a critical issue of food animal production. Moreover, access to information and formation of social values can contribute to the general public demonstrating concern about animal welfare in animal agriculture (Rollin, 2004). In fact, media coverage of cases involving the use and mistreatment of farm animals has been particularly intense in recent years, and in many US states the public has been exposed to an increase in legislative initiatives aimed at addressing farm animal welfare (Centner, 2010). Additionally, food safety crises commonly attributed to industrial animal production systems (e.g., bovine spongiform encephalopathy and Salmonella outbreaks) are frequently highlighted by the media (e.g., Nunez, 2015). It is clear that at least in developed countries the general public has become more interested in farm animal production (Eurobarometer, 2007; Ellis et al., 2009), and a few studies in developing nations suggest a similar trend (Schnettler et al., 2009; Bonamigo et al., 2012; de Barcellos et al., 2013). This increased interest is also reflected by greater media attention, the primary source of information on farming practices for the public (Eurobarometer, 2007; Miele, 2010; Tonsor and Wolf, 2010), which likely influences urban citizens' perceptions of the animal industries (Verbeke and Ward, 2001). Also, animal activism sometimes promotes a negative image of animal industries (for a recent example see Kanso, 2014), which may contribute to some practices (for example, cow-calf separation, Ventura et al., 2013) being rejected by the general public (e.g., Tiplady et al., 2013; Rodan and Mummery, 2014). This link may explain why some of our respondents voiced concerns regarding the treatment received by animals, suggesting that the quality of treatment does not fully match their aspirations. For example, $5.5 \%$ of participants explicitly reported that many cows are currently mistreated on dairy farms, or they argued that the quality of treatment needs to be improved, or labeled the systems as unethical.

\section{CONCLUSIONS}

The main characteristics of an ideal dairy system identified by the respondents were related to animal welfare from 2 perspectives: consideration for the quality of life of the animals, based on ethical arguments, and the consequences of animal care on the quality of milk. We noted preferences for organic systems, smaller family size operations, and rejection of the use of antibiotics and hormones for purposes of increasing production. Respondents also made mention that the farm enterprise should remain productive and profitable. Overall, participants expressed an ethic for dairy farming that includes concerns for the animal and for social and environmental aspects of the dairy system. Our study suggests that providing assurances that animals are well treated, developing methods to incorporate pasture access, and ensuring healthy products without relying on antibiotics or hormones will improve the social sustainability of the dairy industry.

\section{ACKNOWLEDGMENTS}

C. S. Cardoso was awarded the Emerging Leaders in the Americas Program (ELAP) scholarship, which provided funds to support her visit to the Animal Welfare Program, University of British Columbia. Maria J. Hötzel received support from $\mathrm{CNPq}$ (National Council for Scientific and Technological Development, Brazil). Funding was provided in part by CNPq 22/2010 Interinstitutional Network Agroecological Dairy Chain, $562908 / 2010-2$.

\section{REFERENCES}

Bauman, D. E. 1992. Bovine somatotropin: Review of an emerging animal technology. J. Dairy Sci. 75:3432-3451.

Benard, M., and T. De Cock Buning. 2013. Exploring the potential of Dutch pig farmers and urban-citizens to learn through frame reflection. J. Agric. Environ. Ethics 26:1015-1036.

Bonamigo, A., C. B. dos Santos Silva Bonamigo, and C. F. Maiolino Molento. 2012. Broiler meat characteristics relevant to the consumer: Focus on animal welfare. Braz. J. Anim. Sci. 41:1044-1050.

Boogaard, B. K., B. B. Bock, S. J. Oosting, and E. Krogh. 2010. Visiting a farm: An exploratory study of the social construction of animal farming in Norway and the Netherlands based on sensory perception. Int. J. Sociol. Agric. Food 17:24-50.

Boogaard, B. K., S. J. Oosting, and B. B. Bock. 2006. Elements of societal perception of farm animal welfare: A quantitative study in the Netherlands. Livest. Sci. 104:13-22.

Boogaard, B. K., S. J. Oosting, and B. B. Bock. 2008. Defining sustainability as a socio-cultural concept: Citizen panels visiting dairy farms in the Netherlands. Livest. Sci. 117:24-33.

Buhrmester, M., T. Kwang, and S. D. Gosling. 2011. Amazon's Mechanical Turk: A new source of inexpensive, yet high-quality, data? Perspect. Psychol. Sci. 6:3-5.

Centner, T. J. 2010. Limitations on the confinement of food animals in the United States. J. Agric. Environ. Ethics 23:469-486.

Chapinal, N., C. Goldhawk, A. M. de Passillé, M. A. G. von Keyserlingk, D. M. Weary, and J. Rushen. 2010. Overnight access to pasture does not reduce milk production or feed intake in dairy cows. Livest. Sci. 129:104-110.

de Barcellos, M. D., K. G. Grunert, Y. Zhou, W. Verbeke, F. J. A. Perez-Cueto, and A. Krystallis. 2013. Consumer attitudes to dif- 
ferent pig production systems: A study from mainland China. Agric. Human Values 30:443-455.

Ellis, K. A., K. Billington, B. McNeil, and D. E. F. McKeegan. 2009. Public opinion on UK milk marketing and dairy cow welfare. Anim. Welf. 18:267-282.

Eurobarometer. 2007. Attitudes of EU citizens towards animal welfare. Special Eurobarometer 270/Wave 66.1-TNS Opinion \& Social. Page 82.

Fontaneli, R. S., L. E. Sollenberger, R. C. Littell, and C. R. Staples, 2005. Performance of lactating dairy cows managed on pasturebased or in freestall barn-feeding systems. J. Dairy Sci. 88:12641276 .

Fraser, D. 2008. Animal welfare and the intensification of animal production. Pages 167-189 in Ethics of Intensification: Agricultural Development and Cultural Change. Vol. 16. P. B. Thompson, ed. FAO, Rome, Italy.

Fraser, D., D. M. Weary, E. A. Pajor, and B. N. Milligan. 1997. A scientific conception of animal welfare that reflects ethical concerns. Anim. Welf. 6:187-205.

Garnett, T., M. C. Appleby, A. Balmford, I. J. Bateman, T. G. Benton, P. Bloomer, B. Burlingame, M. Dawkins, L. Dolan, D. Fraser, M. Herrero, I. Hoffmann, P. Smith, P. K. Thornton, C. Toulmin, S. J. Vermeulen, and H. C. J. Godfray. 2013. Sustainable intensification in agriculture: Premises and policies. Science 341:33-34.

Gaymard, S., and J. Bordarie. 2015. The perception of the ideal neighborhood: A preamble to implementation of a "street use code". Soc. Indic. Res. 120:801-816.

Godfray, H. C. J., I. R. Crute, L. Haddad, D. Lawrence, J. F. Muir, N. Nisbett, J. Pretty, S. Robinson, C. Toulmin, and R. Whiteley. 2010. The future of the global food system. Philos. Trans. R. Soc. Lond. B Biol. Sci. 365:2769-2777.

Groot Koerkamp, P. W. G., and A. P. Bos. 2008. Designing complex and sustainable agricultural production systems: An integrated and reflexive approach for the case of table egg production in the Netherlands. NJAS-Wageningen. J. Life Sci. 55:113-138.

Hötzel, M. J. 2014. Improving farm animal welfare: Is evolution or revolution needed in production systems? Pages 67-84 in Dilemmas in Animal Welfare. M. C. Appleby, D. M. Weary, and P. Sandoe, ed. CABI, Wallingford, UK.

Huberman, A. M., and M. B. Miles. 1994. Data management and analysis methods. Handbook of Qualitative Research. N. K. Denzin and Y. S. Lincoln, ed. SAGE, Thousand Oaks, CA.

Kanso, H. 2014. World's largest clothing retailer drops angora wool after talks with PETA. Accessed Feb. 11, 2015. http://www. cbsnews.com/news/worlds-largest-clothing-retailer-drops-angorawool-after-talks-with-peta/.

Lassen, J., P. Sandøe, and B. Forkman. 2006. Happy pigs are dirty! Conflicting perspectives on animal welfare. Livest. Sci. 103:221230.

Mason, W., and S. Suri. 2012. Conducting behavioral research on Amazon's Mechanical Turk. Behav. Res. Methods 44:1-23.

Mekonnen, M. M., and A. Y. Hoekstra. 2012. A global assessment of the water footprint of farm animal products. Ecosystems (N. Y.) 15:401-415.

Miele, M. 2010. Report concerning consumer perceptions and attitudes towards farm animal welfare. Official Experts Report EAWP (task 1.3). Vol. Uppsala University, Uppsala, Sweden.

Miele, M., I. Veissier, A. Evans, and R. Botreau. 2011. Animal welfare: A dialogue between science and society. Anim. Welf. 20:103-117.

Moore, K., and W. W. Thatcher. 2006. Major advances associated with reproduction in dairy cattle. J. Dairy Sci. 89:1254-1266.

Nunez, C. 2015. Mad cow disease still menaces U.K. blood supply. Accessed Apr. 25, 2015. http://news.nationalgeographic.com/ news / 2015/02/150215-mad-cow-disease-vcjd-blood-supplyhealth/.

O'Connor, C. E., and A. C. D. Bayvel. 2012. Challenges to implementing animal welfare standards in New Zealand. Anim. Welf. 21:397-401.
Poletto, R., and M. J. Hötzel. 2012. The five freedoms in the global animal agriculture market: Challenges and achievements as opportunities. Anim. Front. 2:22-30.

Prickett, R. W., F. B. Norwood, and J. L. Lusk. 2010. Consumer preferences for farm animal welfare: Results from a telephone survey of US households. Anim. Welf. 19:335-347.

Rodan, D., and J. Mummery. 2014. The "Make it Possible" multimedia campaign: Generating a "New Everyday" in animal welfare. Media International Australia 153:78-87.

Rollin, B. E. 2004. Annual meeting keynote address: Animal agriculture and emerging social ethics for animals. J. Anim. Sci. 82:955964

Rouse, S. V. 2015. A reliability analysis of Mechanical Turk data. Comput. Human Behav. 43:304-307.

Sandøe, P., R. Crisp, and N. Holtug. 1997. Ethics. Pages 3-17 in Animal Welfare. M. C. Appleby and B. O. Hughes, ed. CABI Publishing, Wallingford, UK.

Saunders, D. R., P. J. Bex, and R. L. Woods. 2013. Crowdsourcing a normative natural language dataset: A comparison of Amazon Mechanical Turk and in-lab data collection. J. Med. Internet Res. 15:e100.

Schnettler, B., R. Vidal, R. Silva, L. Vallejos, and N. Sepulveda. 2009. Consumer willingness to pay for beef meat in a developing country: The effect of information regarding country of origin, price and animal handling prior to slaughter. Food Qual. Prefer. 20:156-165.

Schuppli, C. A., M. A. G. von Keyserlingk, and D. M. Weary. 2014 Access to pasture for dairy cows: Responses from an online engagement. J. Anim. Sci. 92:5185-5192.

Te Velde, H., N. Aarts, and C. Van Woerkum. 2002. Dealing with ambivalence: Farmers' and consumers' perceptions of animal welfare in livestock breeding. J. Agric. Environ. Ethics 15:203-219.

Thompson, P. B. 2012. Agriculture, food and society - Philosophy to nanotechnology. Adv. Dairy Technol. 24:53-65.

Tiplady, C. M., D.-A. B. Walsh, and C. J. C. Phillips. 2013. Public response to media coverage of animal cruelty. J. Agric. Environ. Ethics 26:869-885.

Tonsor, G. T., and C. A. Wolf. 2010. Drivers of resident support for animal care oriented ballot initiatives. J. Agric. Appl. Econ. 42:419-428.

Vanhonacker, F., W. Verbeke, E. Van Poucke, and F. A. M. Tuyttens. 2008. Do citizens and farmers interpret the concept of farm animal welfare differently? Livest. Sci. 116:126-136.

Ventura, B. A., M. A. G. von Keyserlingk, C. A. Schuppli, and D. M. Weary. 2013. Views on contentious practices in dairy farming: The case of early cow-calf separation. J. Dairy Sci. 96:6105-6116.

Verbeke, W., and R. W. Ward. 2001. A fresh meat almost ideal demand system incorporating negative TV press and advertising impact. Agric. Econ. 25:359-374.

von Keyserlingk, M. A. G., and M. J. Hötzel. 2015. The ticking clock: Addressing farm animal welfare in emerging countries. J. Agric. Environ. Ethics 28:179-195.

von Keyserlingk, M. A. G., N. P. Martin, E. Kebreab, K. F. Knowlton, R. J. Grant, M. Stephenson II, C. J. Sniffen, J. R. Harner III, A. D. Wright, and S. I. Smith. 2013. Invited review: Sustainability of the US dairy industry. J. Dairy Sci. 96:5405-5425.

Weary, D. M., C. A. Schuppli, and M. A. G. von Keyserlingk. 2011. Tail docking dairy cattle: Responses from an online engagement. J. Anim. Sci. 89:3831-3837.

Weary, D. M., B. A. Ventura, and M. A. G. von Keyserlingk. 2015. Invited Review: Societal views and animal welfare science: Understanding why the modified cage may fail and other stories. Animal http://dx.doi.org/10.1017/S1751731115001160.

White, S. L., G. A. Benson, S. P. Washburn, and J. T. Green Jr.. 2002. Milk production and economic measures in confinement or pasture systems using seasonally calved Holstein and Jersey cows. J. Dairy Sci. 85:95-104. 